\title{
Development of a novel cell-based assay system EPISSAY for screening epigenetic drugs and liposome formulated decitabine
}

Sue Ping Lim", Raman Kumar ${ }^{1,2}$, Yamini Akkamsetty ${ }^{3}$, Wen Wang ${ }^{3}$, Kristen Ho ${ }^{1}$, Paul M Neilsen ${ }^{1}$, Diego J Walther ${ }^{4}$, Rachel J Suetani ${ }^{1}$, Clive Prestidge ${ }^{3}$ and David F Callen ${ }^{1}$

\begin{abstract}
Background: Despite the potential of improving the delivery of epigenetic drugs, the subsequent assessment of changes in their epigenetic activity is largely dependent on the availability of a suitable and rapid screening bioassay. Here, we describe a cell-based assay system for screening gene reactivation.

Methods: A cell-based assay system (EPISSAY) was designed based on a silenced triple-mutated bacterial nitroreductase TMnfsB fused with Red-Fluorescent Protein (RFP) expressed in the non-malignant human breast cell line MCF10A. EPISSAY was validated using the target gene TXNIP, which has previously been shown to respond to epigenetic drugs. The potency of a epigenetic drug model, decitabine, formulated with PEGylated liposomes was also validated using this assay system.

Results: Following treatment with DNA methyltransferase (DNMT) and histone deacetylase (HDAC) inhibitors such as decitabine and vorinostat, increases in RFP expression were observed, indicating expression of RFP-TMnfsB. The EPISSAY system was then used to test the potency of decitabine, before and after PEGylated liposomal encapsulation. We observed a 50\% higher potency of decitabine when encapsulated in PEGylated liposomes, which is likely to be due to its protection from rapid degradation.
\end{abstract}

Conclusions: The EPISSAY bioassay system provides a novel and rapid system to compare the efficiencies of existing and newly formulated drugs that reactivate gene expression.

Keywords: Cell-based assay system, Decitabine, Liposomes, Nanotechnology, CB1954, Nitroreductase

\section{Background}

DNA methylation and histone modification are the two major epigenetic mechanisms catalyzed by DNMTs and HDACs, respectively [1]. HDACs remove the acetyl groups from histones, whilst DNMTs catalyse the transfer of a methyl group from S-adenosylmethionine to the 5-carbon position of the cytosine pyrimidine ring, both leading to the condensation of chromatin to its inactive state $[2,3]$. In cancer cells, an abundance of hypoacetylated histones is usually associated with DNA hyper-methylation and gene silencing [4]. These findings are the basis for the development of HDAC and DNMT

\footnotetext{
* Correspondence: sue.lim@adelaide.edu.au

${ }^{1}$ Cancer Therapeutics Laboratory, Centre for Personalized Cancer Medicine,

The University of Adelaide, Adelaide, South Australia, Australia

Full list of author information is available at the end of the article
}

inhibitors as cancer therapeutics. Such compounds block the activity of HDACs and DNMTs, leading to increased expression of epigenetically silenced genes which mediate cellular and metabolic changes such as cell growth arrest, differentiation and apoptosis [5-9].

Hydrophobic vorinostat (suberoylanilide hydroxamic acid, SAHA) and hydrophilic decitabine (5-aza-2'-deoxycytidine, Dacogen) are US Food and Drug Administration (FDA) approved HDAC and DNMT inhibitors for the treatment of cutaneous T-cell lymphoma and myelodysplastic syndrome, respectively $[10,11]$. The combination of vorinostat and decitabine have been shown to have promising activity in patients with myelodysplastic syndrome without significant toxicity in a phase I clinical trial [12]. Under neutral conditions, decitabine has a reported half-life of 7 days at $4^{\circ} \mathrm{C}$ or 21 hours at $37^{\circ} \mathrm{C}$ in vitro [13]. However, decitabine is

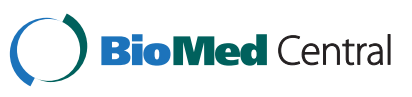


degraded more rapidly in vivo with a half-life of only 25 minutes [13]. Such chemical instability of decitabine has led to its administration in the clinic as a cold and continuous intravenous infusion in an effort to reach the maximal-tolerated doses required to achieve clinical response $[14,15]$.

The development of drug formulation using nanotechnology (e.g. liposomes) has been used to improve drug stability $[16,17]$. Despite the potential of improving the delivery of epigenetic drugs, the subsequent assessment of changes in their epigenetic activity is largely dependent on the availability of a suitable and rapid screening bioassay. A commonly used cell-based assay for both DNMT and HDAC inhibitors is the quantification of the re-expression of known epigenetically-silenced genes by reverse transcription polymerase chain reaction (RT-PCR) and western blot analysis $[5,18]$. However, this traditional approach is not high-throughput and may produce gene-specific results. Other assays that have been used include estimation of global DNA methylation using capillary electrophoresis, DNA digestion with methylation-sensitive restriction enzymes, or analysis of specific DNA methylation using bisulfite sequencing and methylation-specific PCR [19]. However, these assay systems designated for assaying DNMT or HDAC inhibitors are time-consuming, cumbersome and subject to misinterpretation [20-22]. Consequently, the rapid identification and validation of novel epigenetic drugs are hampered due to the lack of an efficient screening method.

In this study, a cell-based assay system was developed to compare the activity of different epigenetic drugs. This assay system is based on mammalian MCF10A cells expressing a fusion protein between red-fluorescent protein (RFP) and bacterial nitroreductase (TMnfsB) driven by CMV promoter. Epigenetic silencing has been shown to silence genes driven by CMV promoter in both stably transfected cells and transgenic pigs $[23,24]$. Silenced CMV promoter driven genes were shown to be reactivated after treatment with epigenetic drugs such as butyrate, trichostatin A and decitabine [23]. Human cells expressing TMnfsB are able to metabolize the monofunctional alkylating prodrug CB1954 (5-(azaridin-1-yl)-2,4-dinitro-benzamide) to highly cytotoxic hydroxylamino- and amino-derivatives, which induce rapid cell death [25]. Therefore, TMnfsB was utilized as a tool to obtain clones with inactivated CMV promoters. The TMnfsB open reading frame has been codon optimized to increase the sensitivity of stable human cell lines to the prodrug CB1954 [26]. An assay system for gene reactivation was developed by identifying clones where expression of RFP-TMnfsB was suppressed at the transcriptional level, but could be re-established by subsequent treatment with epigenetic drugs. Since RFP expression in these clones is low, it was used as a signal to evaluate the reactivation of gene expression by flow cytometry. Using this newly developed assay system, it was shown that decitabine which encapsulated in the liposomes has a higher gene restoring ability than pure decitabine, zebularine and RG108.

\section{Methods \\ Plasmids}

The mammalianized nitroreductase gene $\mathrm{B}(T M n f s B)$ vector was generated by subcloning the nitroreductase open reading frame from existing constructs kindly provided by Grohmann et al. [26] into the pDsRED-C1-monomer vector at a XhoI/BamHI site. A retroviral plasmid pLNCX2-RFP-TMnfs B expressing RFP-TMnfsB fusion was generated by subcloning the $R F P-T M n f s B$ coding fragment from the existing construct pDsRED-TMnfs $B$ (SnaBI/BamHI) into the pLNCX2 vector (SnaBI/BglII). All constructs were confirmed by sequencing using appropriate primers (Additional file 1).

\section{Cell culture}

All human cell lines were purchased from the American Type Culture Collection (ATCC) except the Phoenix retrovirus producer cell line which was kindly provided by Prof. Garry Nolan of Stanford University (United States). All cell lines were grown in the ATCC recommended media.

\section{Reagents}

CB1954 (soluble to $2 \mathrm{mg} / \mathrm{mL}$ in aqueous solution), decitabine (soluble to $50 \mathrm{mg} / \mathrm{mL}$ in aqueous solution), $2(1 \mathrm{H})$-pyrimidinone riboside (zebularine; soluble to $16 \mathrm{mg} / \mathrm{mL}$ in DMSO) and RG108 (soluble to $10 \mathrm{mg} / \mathrm{mL}$ in DMSO) were purchased from Sigma. RG108 is known to be an ineffective DNMT inhibitor [27] and was used as a negative control. Vorinostat $(10 \mathrm{mM})$ was kindly supplied by Dr. Lisa Butler of The University of Adelaide (South Australia). All drugs were dissolved in DMSO except decitabine, which was prepared in water for liposomal formulation. The synthetic lipids 1,2dioleoyl-sn-glycero-3-[phospho-rac-(1-glycerol)] sodium salt (DOPG), 1,2 distearoyl-sn-glycero-3-phosphocholine (DSPC), 1,2-distearoyl-sn-glycero-3-phosphoethanolamine$\mathrm{N}$-[amino(polyethylene glycol)-2000] ammonium salt (DSPE-PEG2000) and natural cholesterol lipid were purchased from Avanti Polar Lipids.

\section{Generation of stable cell line and clonal selection}

Recombinant retrovirus encoding RFP-TMnfsB was produced using the Phoenix packaging cell line transfected with Lipofectamine 2000 (Invitrogen) according to the recommended protocol. Stable cell lines expressing RFPTMnfsB were generated by G418 selection of MCF10A cells transduced with retrovirus expressing RFP-TMnfsB for approximately 2 months. G418-resistant MCF10A cells were grown into colonies in $10 \mathrm{~cm}$ dishes and potential 
clones where TMnfsB was spontaneously silenced were isolated by treating these colonies with $5 \mu \mathrm{M}$ of CB1954 for 72 hours. Surviving colonies, which were potentially epigenetically silenced, were isolated as CB1954-resistant clones. The integrity of RFP-TMnfsB in CB1954-resistant clones was determined by screening using RT-PCR. Finally, colonies with silenced $R F P-T M n f s B$ insert were identified by assessing TMnfsB and RFP expression using RT-PCR and flow cytometry, respectively, after treatment with epigenetic drugs.

\section{Real-time polymerase chain reaction (RT-PCR)}

RNA and DNA from the cells were extracted using the RNeasy plant mini kit (Qiagen) and the DNeasy Blood and Tissue Kit (Qiagen), respectively. cDNA was generated using random primers and $20 \mathrm{U}$ of reverse transcriptase (Promega). TXNIP, TMnfsB and RFP-TMnfsB expression were determined by $\mathrm{qRT}-\mathrm{PCR}$ using $\mathrm{IQ}^{\mathrm{TM}}$ SYBR green supermix (Biorad) and primers listed in Additional file 1. Cycling conditions were: $10 \mathrm{~min}$ at $95^{\circ} \mathrm{C}$ followed by 40 repeats of $95^{\circ} \mathrm{C}$ for $10 \mathrm{~s}$, annealing at appropriate temperature for $15 \mathrm{~s}$ and extension at $72^{\circ} \mathrm{C}$ for $10 \mathrm{~s}$. $\beta$-actin expression was used for normalization of target gene expression.

\section{Western blotting}

Western blot analysis of RFP-TMnfsB fusion protein expressed in MCF10A cells was performed using a rabbit polyclonal anti-RFP antibody (Invitrogen) or mouse anti- $\beta$-actin antibody (Sigma-Aldrich), and a secondary donkey anti-rabbit IgG-HRP (GE Healthcare) or a sheep anti-mouse IgG-HRP (GE Healthcare) [28]. Total cellular proteins were extracted as described previously [29] and visualized by an Enhanced Chemiluminescence Detection Kit (Amersham Biosciences).

\section{Flow cytometry}

The reactivation of silenced RFP-TMnfsB was determined by flow cytometry. Cells were plated at $40 \% 24$ hours prior to treatment. The approximate doubling time of the cells is 48 hours. Cells were treated with each drug (decitabine $1,5,10,30$ and $50 \mu \mathrm{M}$; zebularine $50,100,250$ and $500 \mu \mathrm{M}$; RG108 10 and $100 \mu \mathrm{M}$; vorinostat 1 and $2 \mu \mathrm{M}$ ) for 48 or 72 hours in triplicate. The red-fluorescence of cells was analyzed at a log scale of geometric mean of FL3-H using FACSCalibur flow cytometer (BD). Data were processed using WinMDI v2.8 software.

\section{Preparation of liposomal decitabine}

Liposomal formulations were prepared according to the method developed by Sunoqrot and colleagues with minor modifications [30]. Briefly, $5 \mathrm{mg}$ (32.5 mol\%) DOPG, $4.9 \mathrm{mg}$ (32.1 mol\%) DSPC, $1.8 \mathrm{mg}$ (3.3 mol\%) DSPE-PEG2000 and $2.4 \mathrm{mg}(32.1 \mathrm{~mol} \%)$ cholesterol were dissolved in $5 \mathrm{~mL}$ of chloroform. Thin lipid films were generated after removing the solvent in a rotary evaporator for 2 hours at room temperature. Liposomes were formed when thin lipid films $(4 \mathrm{mM})$ were hydrated in $5 \mathrm{~mL}$ of water or $0.88 \mathrm{mM}$ decitabine dissolved in water for 1 hour at room temperature and stored at $4^{\circ} \mathrm{C}$. The samples were extruded ten times using 200 and $400 \mathrm{~nm}$ polycarbonate membranes to obtain unilamellar liposomes.

\section{High performance liquid chromatography (HPLC)}

HPLC (Shimadzu LC-10AT) analysis was done using a XTerraTM C8 analytical column at $254 \mathrm{~nm}$, using MiliQ water as mobile phase and a flow rate of $0.8 \mathrm{~mL} / \mathrm{min}$. The limit of quantification of decitabine is $10 \mathrm{ng} / \mathrm{mL}[31,32]$.

\section{Liposomes characterization}

The size and zeta potential of liposomes were characterized by dynamic laser light scattering (Malvern Zetasizer Nanoseries). Data are expressed as the mean plus standard deviation of three technical repetitive measurements. For determination of encapsulation efficiency, free decitabine in the supernatant was collected after centrifugation at 82,508 $x g$ for 30 minutes at $4^{\circ} \mathrm{C}$ and measured by HPLC. The encapsulation efficacy of decitabine was defined as the mass ratio between the amount of drugs incorporated in liposomes and that used in the liposome preparation.

\section{Controlled release study of liposomes formulated decitabine}

A controlled release study was performed using dialysis tubing (regenerated cellulose tubing, Mw cut-off 12000 , $43 \mathrm{~mm}$ flat width, Crown Scientific, Australia) incubated in phosphate buffered saline $(\mathrm{PBS})$ at $37^{\circ} \mathrm{C}$. A $0.25 \mathrm{~mL}$ decitabine liposome suspension was added to the dialysis tubing immersed in a beaker with $10 \mathrm{~mL}$ of PBS as the release medium. Aliquots of $0.1 \mathrm{~mL}$ were collected from the solution outside the dialysis tubing at different time points. The volume of PBS was maintained by addition of $0.1 \mathrm{~mL}$ PBS after each withdrawal. The concentration of decitabine in each sample was determined using HPLC.

\section{Statistical analysis}

Data were analyzed by GraphPad Prism (GraphPad Software, Inc.) using unpaired two-tailed t-tests, and linear and nonlinear regression.

\section{Results}

Development of a cell-based assay system EPISSAY for screening epigenetic drugs

The triple-mutated mammalianized version of $n f_{s} B$, $T M n f s B$ [26], was selected for developing the assay system as it showed the highest sensitivity to the lethal effect of CB1954 (Additional file 2). The schematic of the development of cell-based assay system for gene reactivation is in 
Figure 1. A stable MCF10A clone (T1) was generated which expressed the cytomegalovirus (CMV) promoter driven RFP-TMnfsB fusion protein (confirmed by western blot analysis, data not shown).

The CMV promoter is known to be gradually silenced over a period of months in culture and can be reactivated by subsequent treatment with epigenetic drugs [23]. Following growth of T1 for over two months there was increased expression of RFP-TMnfsB fusion protein after treatment with DNMT inhibitors (decitabine and zebularine) by western blot and flow cytometry analyses (Figure 2A). We observed that this was not due to auto-fluorescence of basal MCF10A cells (Figure 2B). This confirmed that the increased of red-fluorescent reading in clone $\mathrm{T} 1$ contained cells is due to the reactivation of silenced RFP-TMnfsB.

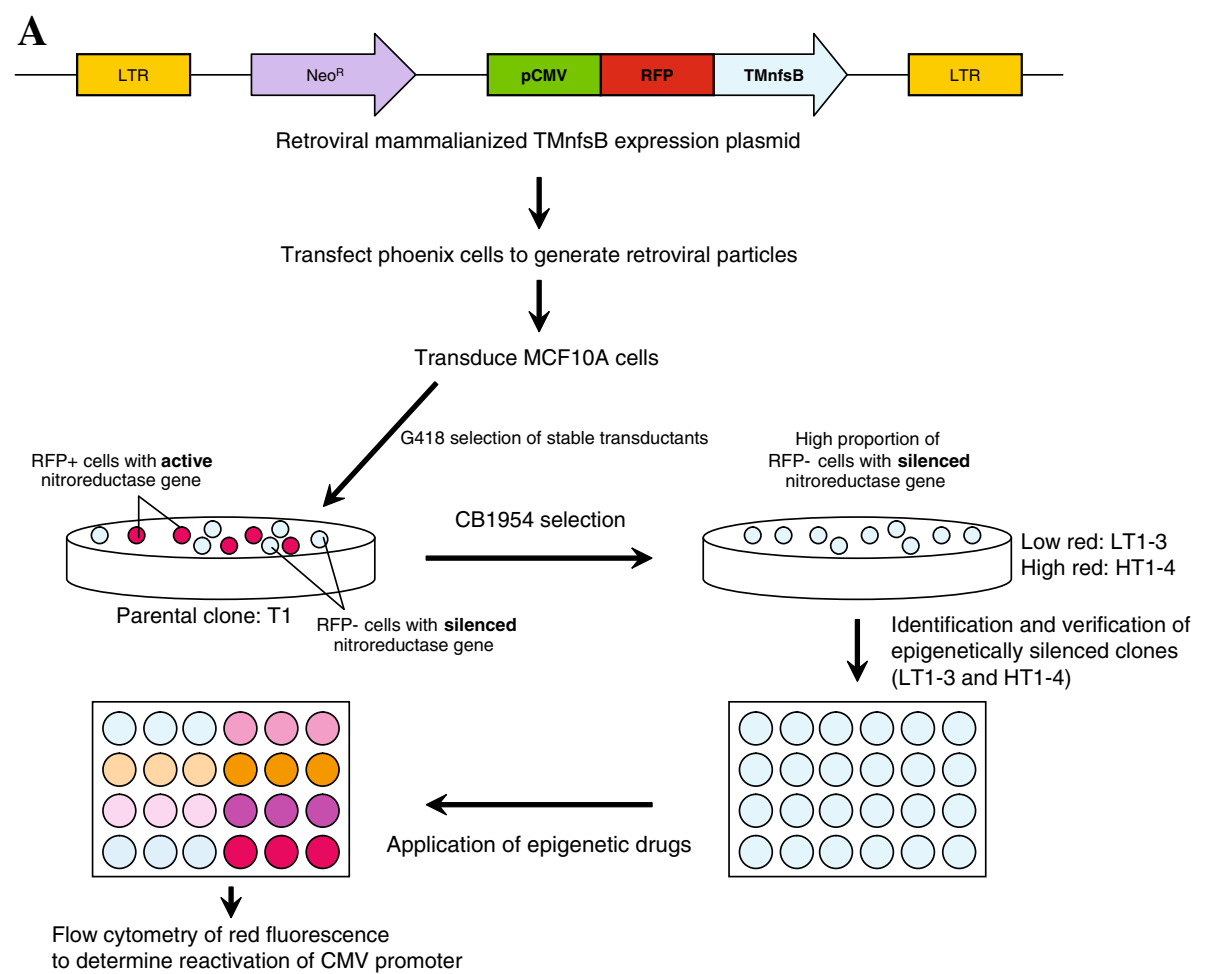

B<smiles>Nc1ncn(C2OC(CO)C(O)CC2(O)CO)c(=O)n1</smiles>

Decitabine

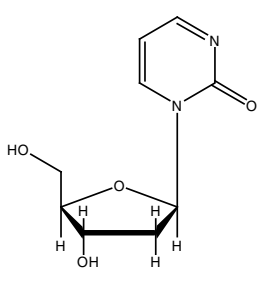

Zebularine<smiles>NC(=O)CCCCCCC(=O)Nc1ccccc1</smiles><smiles>O=C(O)C(Cc1c[nH]c2ccccc12)N1C(=O)c2ccccc2C1=O</smiles>

RG108

Figure 1 The proposed EPISSAY system. (A) Schematic showing different steps in development of the cell-based assay system for testing efficiency of epigenetic drugs. (B) Chemical structure of the epigenetic drugs used in this study. 

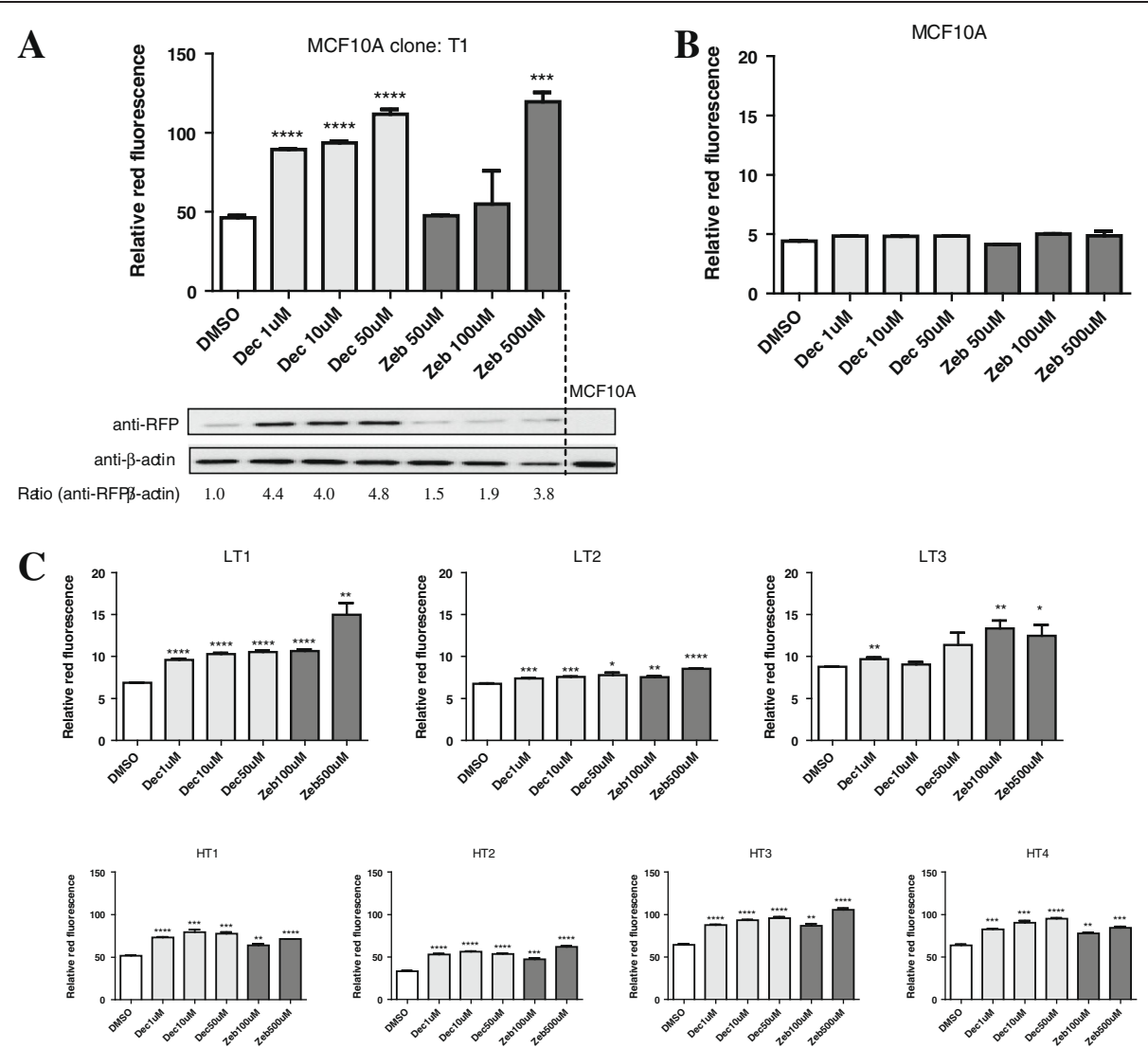

Figure 2 Selection for EPISSAY system. Flow cytometric assessment and western blot of the parental (A) RFP-TMnfsB expressing clone T1 and (B) untransduced MCF10A cells. The densitometry on western blots was quantified using ImageJ program. (C) Flow cytometric assessment of the CB1954-resistant clones generated from T1. Top panel: low fluorescent clones LT1, LT2 and LT3. Bottom panel: high fluorescent clones HT1, HT2, HT3 and HT4. Treatments were: decitabine 1, 10,50 $\mu \mathrm{M}$ or zebularine 50, 100, $500 \mu \mathrm{M}$ for 72 hours in triplicate in $<1 \% \mathrm{v} / \mathrm{v}$ DMSO. Red-fluorescent reading is the gated geometric mean value of FL3-H. Note the different y axis scales for each panel. Unpaired two-tailed $t$-test, data expressed as mean \pm SEM. ${ }^{*}=p<0.05,{ }^{* *}=p<0.01,{ }^{* * *}=p<0.001,{ }^{* * *}=p<0.0001$.

To identify the optimum clone for the basis of the assay system, cells of the T1 clone were treated with CB1954 to kill RFP positive cells which were expressing RFP-TMnfsB. Surviving clones will include those where the CMV promoter was silenced. These were screened for sensitivity to treatment with DNMT inhibitors (Figure 2C). Despite differences in the base levels of red-fluorescence, the red-fluorescent signals of all clones increased after treatment with decitabine and zebularine with clone LT1 showed the highest sensitivity.

\section{Proof of principle of the assay system}

Three clones, LT1, LT3 and HT2, selected for additional testing were treated with decitabine and/or vorinostat for 72 hours, with media changes every 24 hours to maintain drug levels. An increased level of red-fluorescence was observed after treatment in all three clones (Figure 3A). Since the red-fluorescent signal should reflect expression of the $R F P-T M n f s B$ gene, levels of $T M n f s B$ mRNA were quantified in the treated cells (Figure 3B). There was a significant correlation between levels of red-fluorescence and $T M n f_{s} B$ expression in the clones with low and high initial redfluorescence, LT3 and HT2, treated with decitabine and/or vorinostat $(\mathrm{p}<0.0001)$, confirming that the red-fluorescent signal is directly related to the levels of $T M n f s B$ message.

Among these clones, LT1 showed a lower red-fluorescent background and reasonable sensitivity to treatment with epigenetic drugs (Figures 2 and 3). To further validate these findings, the reactivation of two independent endogenous target genes was also assayed. The genes chosen were TXNIP (thioredoxin interacting protein) and ANKRD11 (ankyrin repeat domain 11 protein), which were previously shown to be reactivated after treatment with decitabine and/or vorinostat $[5,33,34]$. The amount of TXNIP and ANKRD11 in the LT1 cells was assessed after treatment with decitabine and/or vorinostat. A linear relationship of red-fluorescence and TXNIP mRNA expression $(\mathrm{p}<0.05)$, and ANKRD11 mRNA expression ( $\mathrm{p}<0.05)$, was observed (Figure $3 \mathrm{C}$ and $3 \mathrm{D}$ ). Taken together, our data clearly show that increases in the levels of red-fluorescence signal are 


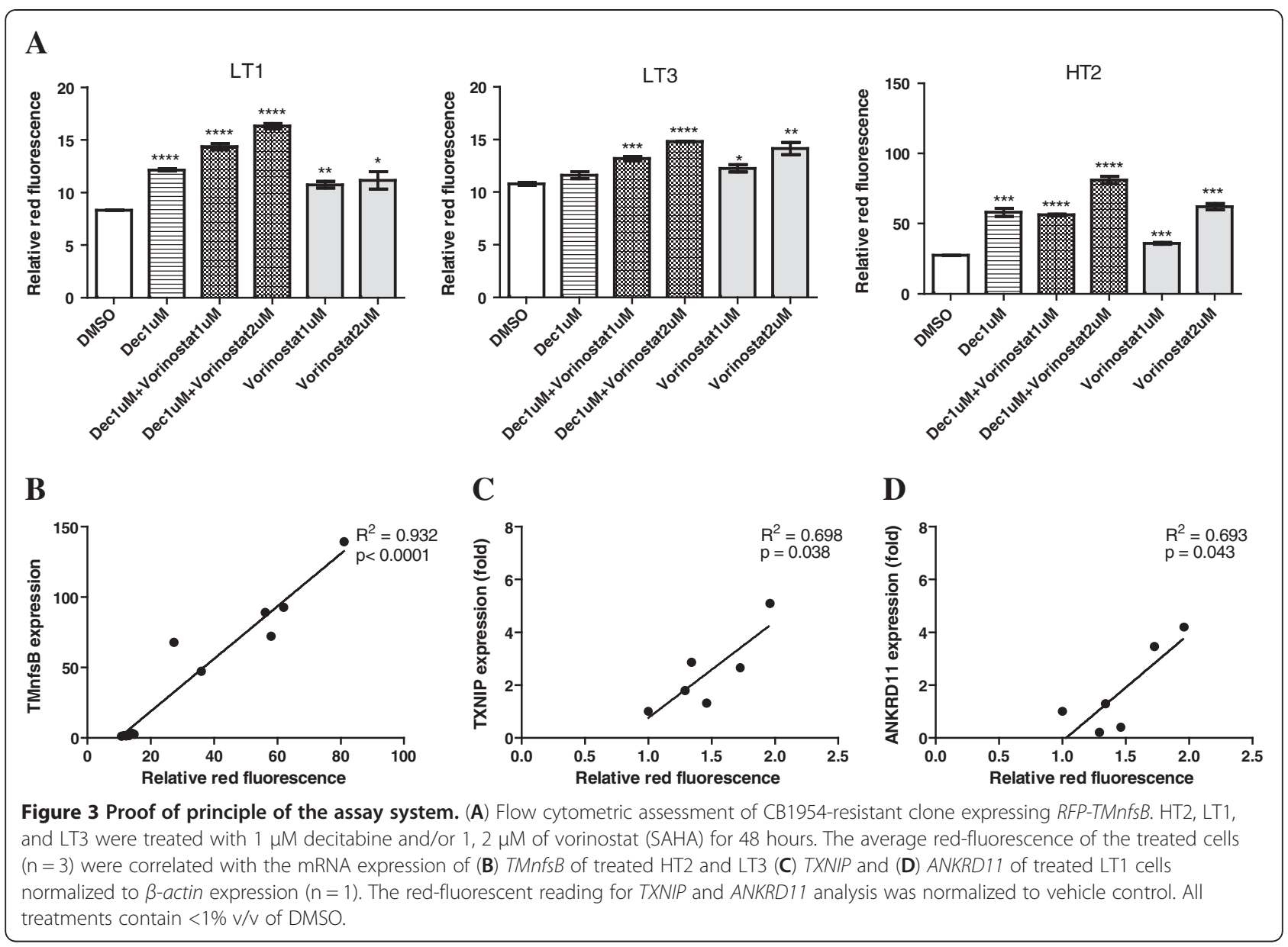

directly correlated with the endogenous TXNIP and $A N K R D 11$ reactivation in the cells treated with epigenetic drugs. We have named LT1 clone as EPISSAY and selected it for screening the activity of epigenetic drugs. We used EPISSAY to determine the effectiveness of a liposomal formulation of decitabine and to compare the existing epigenetic drugs.

\section{Development of liposomal formulated decitabine}

Decitabine is an unstable compound that undergoes hydrolysis [32] and degradation by cytidine deaminase [35]. To improve the stability and bioavailability of decitabine, we formulated decitabine loaded liposomes by thin-film hydration as multilamellar liposomes with a broad size distribution of $871 \pm 69 \mathrm{~nm}$ (Table 1). A narrow size distribution of decitabine-loaded liposomes was obtained by extruding the suspension through $400 \mathrm{~nm}$ and $200 \mathrm{~nm}$ filters to achieve a size of $138 \pm 5 \mathrm{~nm}$ as unilamellar liposomes. The polydispersity index (PDI) of these extruded liposomes was less than 0.5 of the scale of 1 and liposomal formulation achieved an encapsulation efficacy of $55.1 \pm 3.4 \%$ (0.15 $\mathrm{\mu g}$ decitabine/mg of lipid). The zeta potential of decitabine-loaded liposomes before extrusion was similar to the empty liposomes. The zeta potential of decitabineloaded liposomes before extrusion $-69.9 \pm 2.8$ increased to $-40.2 \pm 4.3 \mathrm{mV}$ after extrusion. Overall the physiochemical data confirmed the decitabine-loaded liposomes are highly dispersed and achieved a smaller size $<150 \mathrm{~nm}$ after extrusion. The potency of these newly formulated decitabine-loaded liposomes was subsequently compared with the free drug using the EPISSAY system.

\section{Use of EPISSAY system to determine the potency of liposomal formulated decitabine}

To compare the potency of a panel of epigenetic drugs and newly formulated decitabine, LT1 cells were treated with these drugs for 72 hours, with or without a media change with fresh drug every 24 hours. Continuous treatment is often required as genes can be re-methylated after the removal of decitabine [36]. With a media change, $2 \mu \mathrm{M}$ vorinostat and unilamellar decitabine-loaded liposomes at $30 \mu \mathrm{M}$ were found to be more potent than pure decitabine and zebularine (Figure 4A). Notably, we observed a linear dose-dependent response in cells treated with unilamellar decitabine-loaded liposomes from 5 to $30 \mu \mathrm{M}$. There is a $50 \%$ increase of potency of the unilamellar decitabine- 
Table 1 The physiochemical characteristics of the liposomal formulated decitabine

\begin{tabular}{lccc}
\hline Sample & $\begin{array}{c}\text { Mean diameter, } \\
\mathbf{n m}( \pm \text { SD) }\end{array}$ & $\begin{array}{c}\text { PDI } \\
\text { Zeta potential, } \\
\mathbf{m V}( \pm \text { SD) }\end{array}$ \\
\hline Decitabine-loaded liposomes & $871 \pm 69$ & 0.358 & $-69.9 \pm 2.8$ \\
Decitabine-loaded liposomes (E) & $138 \pm 5$ & 0.296 & $-40.2 \pm 4.3$ \\
Drug-free liposomes (MLVS) & $1070 \pm 77$ & 0.744 & $-60.6 \pm 2.7$ \\
Drug-free liposomes (E) & $146 \pm 1.6$ & 0.137 & $-56.8 \pm 0.9$
\end{tabular}

*E: unilamellar liposomes extruded using 200 and $400 \mathrm{~nm}$ polycarbonate membranes.

PDI: polydispersity index.

MLVs: multilamellar vesicles.

loaded liposomes compared with pure decitabine at $30 \mu \mathrm{M}$. In both with and without a media change, no significant difference was observed between treatment with $2 \mu \mathrm{M}$ vorinostat alone and in the presence of $1 \mu \mathrm{M}$ decitabine.

To investigate whether liposomal formulation protects decitabine from degradation, LT1 cells were treated with different concentrations of decitabine and liposomal decitabine for 72 hours without a media change (Figure 4B). A study of the drug release profile showed that $50 \%$ of decitabine was released from both unilamellar and multilamellar liposomes at $\sim 90$ minutes (Additional file 3). At 4 hours, the release of decitabine from unilamellar liposomes was slower (65\%) than multilamellar liposomes (80\%), confirming the better potency of unilamellar decitabine observed in Figure 4.

The potency of multilamellar decitabine-loaded liposomes and pure decitabine without media change were lower than those with the media change (Figure $4 \mathrm{~A}$ and $\mathrm{B}$ ). Nevertheless, the potency of unilamellar decitabine-loaded liposomes $(10 \mu \mathrm{M})$ was maintained. Although unilamellar decitabine-loaded liposomes $(30 \mu \mathrm{M})$ have the highest potency without media change, this was slightly reduced in comparison with replacing the drug every 24 hours. Taken together, our data showed that the potency of decitabine is improved when delivered as a unilamellar liposomal formulation.

\section{Discussion}

EPISSAY, a cell-based assay system for screening of epigenetic drugs was developed based on the human nonmalignant breast epithelial cell line MCF10A expressing the well-characterized CMV promoter driving RFP fused with a mammalianized version of the bacterial nitroreductase $n f s$ gene. The $n f s$ gene has been used in gene-directed enzyme prodrug therapy [37] since treatment of mammalian cells expressing $n f s$ with CB1954 results in its chemical reduction to cytotoxic metabolites. Exposure of the derivative MCF10A with CB1954 was used as a strategy for the selection of cell lines with silenced $n f s$ genes.

The EPISSAY was verified by treatment with the known epigenetic drugs decitabine, zebularine or vorinostat; all of which resulted in increased red-fluorescence due to reactivation of the CMV promoter. There was a linear relationship between $n f s$ expression and the redfluorescent signal confirming that levels of gene message and translated protein are directly related. The response was further confirmed by measuring expression levels of known independent endogenous genes TXNIP [5] and ANKRD11 [34].

EPISSAY could be a time-saving assay for screening compounds with gene reactivating activity. Standard methodologies used to assess epigenetic compounds are based on quantitative real-time PCR and western blot analysis of genes known to be silenced in a particular cell line. For example, quantification of the re-expression of an endogenous gene p16 in human T24 bladder carcinoma cell line was previously used [38]. Such approaches are time-consuming as they require cell collection for RNA and protein extractions prior to analysis. Other cell-based assay systems which use exogenous expression of genes (e.g. Escherichia coli $\beta$-D-galactosidase gene with and green fluorescent reporter) have previously been investigated for their potential in screening epigenetic drugs by using fluorescent microscopy and plate readers. However, these other systems have limitations such as the nonquantitative data obtained and/or additional sample treatments required (e.g Paraformaldehyde fixing, the addition fluorogenic compounds) prior to screening [18-20] (Additional file 4). EPISSAY requires limited sample preparation, may be formatted for multi-well plates, and rapid results can be generated from RFP reading using flow cytometry to obtain quantitative data.

Decitabine is a demethylating agent that is FDA approved as an anti-cancer agent [13]. Since decitabine is degraded in vivo with a half-life of only 25 minutes, daily treatments are required to maintain appropriate drug levels both in vitro and in vivo [39]. To improve the stability and bioavailability of decitabine, the drug was encapsulated in PEGylated liposomes, as liposomes are known to protect drugs from degradation and allow controlled release of drug into the environment [40]. This formulation achieved an encapsulation efficiency of $\sim 50 \%$. Only $3.3 \mathrm{~mol} \%$ of PEG 2000 was used in this study as a higher PEG content is known to reduce adsorption of liposomes onto cells [41].

Liposomes were extruded through filters with defined pore size (200 nm and $400 \mathrm{~nm}$ ) to obtain unilamellar liposomes. Although extrusion does not affect the encapsulation efficiency [42], it narrowed the size distribution of the liposomes from $1 \mu \mathrm{m}$ to approximately $150 \mathrm{~nm}$. The smaller size of the drug-loaded liposomes has been reported to passively targeting disease tissues due to their enhanced angiogenesis [43].

We used the EPISSAY system to determine if liposomal encapsulation enhanced the gene reactivating activity of decitabine. Following 72 hours of treatment, decitabine 

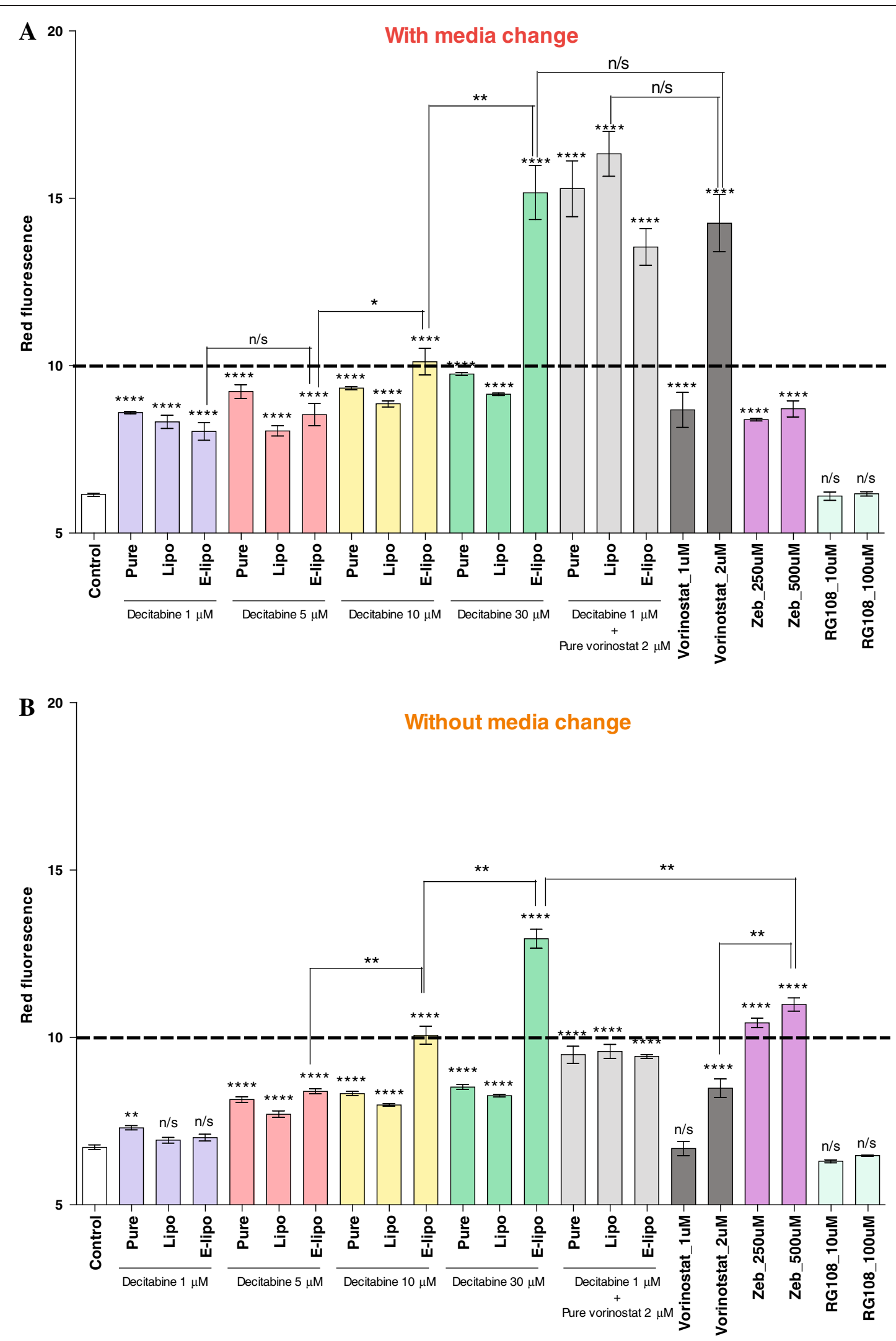

Figure 4 (See legend on next page.) 
(See figure on previous page.)

Figure 4 The comparison of pure and newly-formulated epigenetic drugs using EPISSAY. Flow cytometric assessment of LT1 cells treated with epigenetic drugs. Treatments were: liposomal formulated or pure decitabine 1, 5, 10, $30 \mu \mathrm{M}$ and/or pure vorinostat 1, $2 \mu \mathrm{M}$; pure zebularine 250, $500 \mu \mathrm{M}$; pure RG108 10, $100 \mu \mathrm{M}$ (A) with or (B) without media change for 72 hours in triplicate. The gated geometric mean values of FL3-H (red-fluorescence) were normalized to the vehicle control, drug-free liposomes and water. Lipo: multilamellar decitabine-loaded liposomes; E-lipo: unilamellar decitabine-loaded liposomes. Pure: drug without modification. Unpaired two-tailed $t$-test, data expressed as mean $\pm \mathrm{SEM}$. ${ }^{*}=\mathrm{p}<0.05$, ${ }^{* *}=p<0.01,{ }^{* * *}=p<0.001,{ }^{* * * *}=p<0.0001$.

encapsulated in unilamellar liposomes showed $50 \%$ more potency than pure decitabine, suggesting that decitabine was protected in the liposomes and slowly released into the media. These results were supported by a controlled release study comparing the drug release of decitabine from unilamellar and multilamellar liposomes. This showed that the release rate of decitabine from unilamellar liposomes was slower, suggesting unilamellar liposomal formulation may decrease the rate of degradation of decitabine by providing protection to the drug. In addition, the liposomal formulation and the presence of phospholipids in the cell media could also contribute to the enhancement of decitabine activity [44,45].

Collectively, the liposomal decitabine that was synthesised here was validated as a more potent epigenetic drug. However, we have only confirmed this in vitro. An in vivo study of liposomal decitabine is recommended to assess its applicability for clinical use, and to confirm if the present limitations of decitabine use in the clinic could be overcome by this formulation. The use of liposomes/ PEG to encapsulate drugs to improve their bio-availability and stability is now gaining momentum with a number of drugs eg doxorubicin [17], rhenium radionuclides [46] and dexamethasone phosphate [47], liposome-encapsulated doxorubicin now having FDA approval.

\section{Conclusions}

In this pilot study, we have constructed and evaluated a novel bioassay for epigenetic compounds. The readout of the EPISSAY system is red-fluorescence, which may allow the adaptation of the assay system to a multi-well format allowing high throughput, rapid, and cheap bioassay in the future. EPISSAY was successful in providing evaluation of different liposomal formulations of decitabine. The EPISSAY can detect the gene reactivating effects of decitabine, zebularine or vorinostat. Linear correlation between the message of an endogenous gene ANKRD11 and red-fluorescent reading has been shown in the EPISSAY cells treated with pure decitabine and unilamellar liposomes-formulated decitabine (Additional file 5).

Using SEQUENOM MassARRAY EpiTYPER, no major changes in methylation of the CMV promoter was detected in the EPISSAY cells before and after treatments with decitabine (Additional file 6 and 7). Although vorinostat is known as a HDAC inhibitor to activate gene expression, zebularine and decitabine are usually considered to function as demethylating agents or DNMT inhibitors [48]. However, there are now multiple studies that show these agents can also function as HDAC inhibitors [49-51]. This suggests that the $T M n f s B$ gene was most likely silenced by histone modification rather than direct methylation of the CMV promoter. There is a potential of adopting this assay as a high throughput, rapid and low cost epigenetic drug screening platform are unique aspects of the EPISSAY system. We conclude that our EPISSAY bioassay system provides a novel and rapid system to screen the efficiencies of epigenetic and newly formulated drugs for gene reactivation.

\section{Additional files}

\section{Additional file 1: PCR primers used in this study.}

Additional file 2: Sensitivity of different nitroreductase genes to CB1954. Transiently transfected HEK293T cells with (A) pDsREDmonomer-C1 vector, (B) pDsRED-nfsA, (C) pDsRED-nfsB, (D) pDsREDMnfsB, (E) pDsRED-TMnfsB and incubated with 0, 1, 5, $10 \mu \mathrm{M}$ of CB1954 for 24 hours at $37^{\circ} \mathrm{C} / 5 \% \mathrm{CO}_{2}$. All contain $0.2 \% \mathrm{v} / \mathrm{V}$ DMSO. The decreased of red-fluorescence indicates cell death.

Additional file 3: Controlled release study of liposomal decitabine. (A) The standard plot of pure decitabine produced using HPLC at 254 $\mathrm{nm}$ (retention time $=6.554 \pm 0.003$ minutes). (B) Drug release profiles of unilamellar and multilamellar liposomal decitabine at different time intervals generated using the standard plot of pure decitabine.

Additional file 4: Characteristics of previously investigated epigenetic cell-based assay systems.

Additional file 5: The correlation of endogenous ANKRD11 expression and the relative red-fluorescence in the EPISSAY system. The average red-fluorescence of the treated cells $(n=3)$ were correlated with the mRNA expression of ANKRD11 ( $n=1)$. The EPISSAY (LT1) cells were treated with 1, 5, 10, $30 \mu \mathrm{M}$ of pure decitabine and unilamellar liposomes-formulated decitabine for 72 hours with/ without a media change every 24 hours to replenish the level of drugs. ANKRD11 of treated LT1 cells was normalized to $\beta$-actin expression. The redfluorescent reading was normalized to vehicle control.

Additional file 6: Epigram showing methylation levels of the CMV promoter generated from SEQUENOM EpiTYPER Platform. This epigram showed \% CpG methylation of CMV promoter in overlapping regions of CMV_1 and CMV_2 amplicons of RFP-TMnfsB expressing clones treated with epigenetic drugs are indicated $(n=2)$. Dec: decitabine; Zeb: zebularine. LT1 is the CB1954-resistant clone, which subsequently in used as the basis of EPISSAY. T1 is the parental clone without CB1954 selection and has a higher red-fluorescent background than LT1. The CpG units are as defined in Addition file 7.

Additional file 7: Amplicon design and the target region for methylation analysis. Bisulfite treated sequence of CMV promoter regions: CMV_1; CMV_2. [T bold: cytosine from non-CG converted to T; italic smaller font: primer target sequence; all CGs: bold; CG underlined: analysed CGs; |Unit|: fragment with different mass and size generated by enzymatic base specific cleavage]. 


\section{Competing interests}

The authors declare that they have no competing interests.

\section{Authors' contributions}

SPL carried out all the experimental work and drafted the manuscript. RK carried out the molecular biology studies, participated in the experimental design and contributed to drafting and editing of the manuscript. YA and WW participated in the study of nanotechnology. KH, PMN and DJW contributed to the molecular biology studies. RJS was involved in the design of the study, performed the statistical analysis and edited the manuscript. CP reviewed the study and participated in the nanotechnology work. DFC supervised the study, and contributed to its design and coordination and helped to draft the manuscript. All authors read and approved the final manuscript.

\section{Acknowledgements}

The authors have no conflict of interest directly related to the content of this paper.

\section{Author details}

${ }^{1}$ Cancer Therapeutics Laboratory, Centre for Personalized Cancer Medicine, The University of Adelaide, Adelaide, South Australia, Australia. 'Women's \& Children's Health Research Institute Inc, North Adelaide, South Australia, Australia. ${ }^{3}$ Ian Wark Research Institute, University of South Australia, Mawson Lakes Boulevard, Mawson Lakes, South Australia, Australia. ${ }^{4}$ Max Planck Institute for Molecular Genetics, Berlin, Germany.

Received: 8 October 2012 Accepted: 5 March 2013

Published: 13 March 2013

\section{References}

1. Richards EJ, Elgin SCR: Epigenetic Codes for Heterochromatin Formation and Silencing: Rounding up the Usual Suspects. Cell 2002, 108:489-500.

2. de Ruijter AJM, van Gennip AH, Caron HN, Kemp S, van Kuilenburg ABP: Histone deacetylases (HDACs): characterization of the classical HDAC family. Biochem J 2003, 370:737-749.

3. Burgers WA, Fuks F, Kouzarides T: DNA methyltransferases get connected to chromatin. Trends Genet 2002, 18:275-277.

4. Ballestar E, Esteller M: The impact of chromatin in human cancer: linking DNA methylation to gene silencing. Carcinogenesis 2002, 23:1103-1109.

5. Butler LM, Zhou X, Xu W-S, Scher HI, Rifkind RA, Marks PA, Richon VM: The histone deacetylase inhibitor SAHA arrests cancer cell growth, up-regulates thioredoxin-binding protein-2, and down-regulates thioredoxin. Proc Natl Acad Sci 2002, 99:11700-11705.

6. Lyko F, Brown R: DNA Methyltransferase Inhibitors and the Development of Epigenetic Cancer Therapies. J Natl Canc Inst 2005, 97:1498-1506.

7. Gottlicher M, Minucci S, Zhu P, Kramer OH, Schimpf A, Giavara S, Sleeman JP, Lo Coco F, Nervi C, Pelicci PG, Heinzel T: Valproic acid defines a novel class of HDAC inhibitors inducing differentiation of transformed cells. EMBO J 2001, 20:6969-6978.

8. Singh TR, Shankar S, Srivastava RK: HDAC inhibitors enhance the apoptosis-inducing potential of TRAIL in breast carcinoma. Oncogene 2005, 24:4609-4623.

9. Baylin SB: DNA methylation and gene silencing in cancer. Nat Clin Pract 2005, 2:4-11.

10. Kantarjian H, Issa J-PJ, Rosenfeld CS, Bennett JM, Albitar M, DiPersio J, Klimek $\checkmark$, Slack J, de Castro C, Ravandi F, et al: Decitabine improves patient outcomes in myelodysplastic syndromes. Cancer 2006, 106:1794-1803.

11. Santini V, Gozzini A, Ferrari G: Histone Deacetylase Inhibitors: Molecular and Biological Activity as a Premise to Clinical Application. Curr Drug Metab 2007, 8:383-394.

12. Kirschbaum M, Gojo I, Goldberg SL, Kujawski L, Atallah E, Marks P, Gravio DD, Pyle L, Rizvi S, Issa J-PJ: Vorinostat in Combination with Decitabine for the Treatment of Relapsed or Newly Diagnosed Acute Myelogenous Leukemia (AML) or Myelodysplastic Syndrome (MDS): A Phase I, Dose-Escalation Study. ASH Annual Meeting Abstracts 2089, 2009:114.

13. Stresemann C, Lyko F: Modes of action of the DNA methyltransferase inhibitors azacytidine and decitabine. Int J Cancer 2008, 123:8-13.

14. Samlowski WE, Leachman SA, Wade M, Cassidy P, Porter-Gill P, Busby L, Wheeler R, Boucher K, Fitzpatrick F, Jones DA, Karpf AR: Evaluation of a 7-Day Continuous Intravenous Infusion of Decitabine: Inhibition of
Promoter-Specific and Global Genomic DNA Methylation. J Clin Oncol 2005, 23:3897-3905.

15. Issa JJ, Garcia-Manero G, Giles FJ, Mannari R, Thomas D, Faderi S, Bayar E, Lyons J, Rosenfeld CS, Cortes J, Kantarjian HM: Phase I study of low-dose prolonged exposure schedules of the hypomethylating agent 5-aza-2'deoxycytidine (decitabine) in hematopoietic malignancies. Blood 2004, 103:1635-1640.

16. Smith AM, Jaime-Fonseca MR, Grover LM, Bakalis S: Alginate-Loaded Liposomes Can Protect Encapsulated Alkaline Phosphatase Functionality When Exposed to Gastric pH. J Agric Food Chem 2010, 58:4719-4724.

17. Rose PG: Pegylated Liposomal Doxorubicin: Optimizing the Dosing Schedule in Ovarian Cancer. Oncologist 2005, 10:205-214.

18. Byun H-M, Choi SH, Laird PW, Trinh B, Siddiqui MA, Marquez VE, Yang AS: 2/-Deoxy-N4-[2-(4-nitrophenyl) ethoxycarbonyl]-5-azacytidine: a novel inhibitor of DNA methyltransferase that requires activation by human carboxylesterase 1. Cancer Lett 2008, 266:238-248.

19. Villar-Garea A, Fraga MF, Espada J, Esteller M: Procaine Is a DNA-demethylating Agent with Growth-inhibitory Effects in Human Cancer Cells. Cancer Res 2003 63:4984-4989.

20. Biard DSF, Cordier A, Sarasin A: Establishment of a human cell line for the detection of demethylating agents. Exp Cell Res 1992, 200:263-271.

21. Okochi-Takada E, Ichimura S, Kaneda A, Sugimura T, Ushijima T: Establishment of a detection system for demethylating agents using an endogenous promoter CpG island. Mutat Res Fundam Mol Mech Mutagen 2004, 568:187-194.

22. Hassig CA, Symons KT, Guo X, Nguyen P-M, Annable T, Wash PL, Payne JE, Jenkins DA, Bonnefous C, Trotter C, et al: KD5170, a novel mercaptoketonebased histone deacetylase inhibitor that exhibits broad spectrum antitumor activity in vitro and in vivo. Mol Cancer Ther 2008, 7:1054-1065.

23. Choi K, Basma H, Singh J, Cheng P-W: Activation of CMV promoter-controlled glycosyltransferase and $\beta$-galactosidase glycogenes by butyrate, tricostatin A, and 5-Aza-2/-deoxycytidine. Glycoconj J 2005, 22:63-69.

24. Kong Q, Wu M, Huan Y, Zhang L, Liu H, Bou G, Luo Y, Mu Y, Liu Z Transgene Expression Is Associated with Copy Number and Cytomegalovirus Promoter Methylation in Transgenic Pigs. PLoS One 2009, 4:e6679.

25. Denny WA: Nitroreductase-based GDEPT. Curr Pharm Des 2002, 8:1349-1361

26. Grohmann M, Paulmann N, Fleischhauer S, Vowinckel J, Priller J, Walther D: A mammalianized synthetic nitroreductase gene for high-level expression. BMC Canc 2009, 9:301.

27. Lim SP, Neilsen P, Kumar R, Abell A, Callen DF: The application of delivery systems for DNA methyltransferase inhibitors. BioDrugs 2011, 25:227-242.

28. Kumar R, Cheney KM, McKirdy R, Neilsen PM, Schulz RB, Lee J, Cohen J, Booker GW, Callen DF: CBFA2T3-ZNF652 Corepressor Complex Regulates Transcription of the E-box Gene HEB. J Biol Chem 2008, 283:19026-19038.

29. Kumar R, Manning J, Spendlove HE, Kremmidiotis G, McKirdy R, Lee J, Millband DN, Cheney KM, Stampfer MR, Dwivedi PP, et al: ZNF652, A Novel Zinc Finger Protein, Interacts with the Putative Breast Tumor Suppressor CBFA2T3 to Repress Transcription. Mol Canc Res 2006, 4:655-665.

30. Sunogrot S, Bae JW, Jin S-E M, Pearson R, Liu Y, Hong S: Kinetically Controlled Cellular Interactions of Polymer-Polymer and PolymerLiposome Nanohybrid Systems. Bioconjug Chem 2011, 22:466-474.

31. Patel K, Guichard SM, Jodrell DI: Simultaneous determination of decitabine and vorinostat (Suberoylanalide hydroxamic acid, SAHA) by liquid chromatography tandem mass spectrometry for clinical studies. J Chromatogr B 2008, 863:19-25.

32. Lin K-T, Momparlerm RL, Rivard GE: High-performance liquid chromatographic analysis of chemical stability of 5-aza-2/-deoxycytidine. J Pharm Sci 1981, 70:1228-1232.

33. Ahsan MK, Masutani H, Yamaguchi Y, Kim YC, Nosaka K, Matsuoka M, Nishinaka Y, Maeda M, Yodoi J: Loss of interleukin-2-dependency in HTLVl-infected T cells on gene silencing of thioredoxin-binding protein-2. Oncogene 2006, 25:2181-2191.

34. Lim SP, Wong NC, Suetani RJ, Ho K, Ng JL, Neilsen PM, Gill PG, Kumar R, Callen DF: Specific-site methylation of tumour suppressor ANKRD11 in breast cancer. Eur J Cancer 2012, 48:3300-3309.

35. Chabot GG, Bouchard J, Momparler RL: Kinetics of deamination of 5-aza-2'deoxycytidine and cytosine arabinoside by human liver cytidine deaminase and its inhibition by 3-deazauridine, thymidine or uracil arabinoside. Biochem Pharmacol 1983, 32:1327-1328. 
36. Si J, Boumber YA, Shu J, Qin T, Ahmed S, He R, Jelinek J, Issa J-PJ: Chromatin remodeling is required for gene reactivation after Decitabinemediated DNA hypomethylation. Cancer Res 2010, 70:6968-6977.

37. Mitchell DJ, Minchin RF: E. coli nitroreductase/CB1954 gene-directed enzyme prodrug therapy: role of arylamine $\mathrm{N}$-acetlytransferase 2. Canc Gene Ther 2008, 15:758-764.

38. Cheng JC, Matsen CB, Gonzales FA, Ye W, Greer S, Marquez VE, Jones PA, Selker EU: Inhibition of DNA Methylation and Reactivation of Silenced Genes by Zebularine. J Natl Canc Inst 2003, 95:399-409.

39. Hollenbach PW, Nguyen AN, Brady H, Williams M, Ning Y, Richard N, Krushel L, Aukerman SL, Heise C, MacBeth KJ: A Comparison of Azacitidine and Decitabine Activities in Acute Myeloid Leukemia Cell Lines. PLoS One 2010, 5:e9001.

40. Immordino ML, Dosio F, Cattel L: Stealth liposomes: review of the basic science, rationale, and clinical applications, existing and potential. Int J Nanomedicine 2006, 1:297-315.

41. Er Y, Barnes TJ, Fornasiero D, Prestidge CA: The encapsulation and release of guanosine from PEGylated liposomes. J Liposome Res 2009, 19:29-36.

42. Colletier J-P, Chaize B, Winterhalter M, Fournier D: Protein encapsulation in liposomes: efficiency depends on interactions between protein and phospholipid bilayer. BMC Biotechnol 2002, 2:9.

43. Maruyama K, Ishida O, Takizawa T, Moribe K: Possibility of active targeting to tumor tissues with liposomes. Adv Drug Deliv Rev 1999, 40:89-102.

44. McAllister SM, Alpar HO, Brown MR: Antimicrobial properties of liposomal polymyxin B. J Antimicrob Chemother 1999, 43:203-210.

45. Egbaria K, Weiner N: Liposomes as a topical drug delivery system. Adv Drug Deliv Rev 1990, 5:287-300.

46. Hrycushko BA, Li S, Goins B, Otto RA, Bao A: Direct intratumoral infusion of liposome encapsulated rhenium radionuclides for cancer therapy: effects of nonuniform intratumoral dose distribution. Med Phys 2011, 38:1339-1347.

47. Anderson R, Franch A, Castell M, Perez-Cano FJ, Brauer R, Pohlers D, Gajda M, Siskos AP, Katsila T, Tamvakopoulos C, et al: Liposomal encapsulation enhances and prolongs the anti-inflammatory effects of water-soluble dexamethasone phosphate in experimental adjuvant arthritis. Arthritis Res Ther 2010, 12:R147.

48. Daskalakis M, Blagitko-Dorfs N, Hackanson B: Decitabine. Oncology: In Small Molecules in; 2010:131-157.

49. Halaban R, Krauthammer M, Pelizzola M, Cheng E, Kovacs D, Sznol M, Ariyan S, Narayan D, Bacchiocchi A, Molinaro A, et al: Integrative Analysis of Epigenetic Modulation in Melanoma Cell Response to Decitabine: Clinical Implications. PLoS One 2009, 4:e4563.

50. Scott SA, Dong W-F, Ichinohasama R, Hirsch C, Sheridan D, Sanche SE, Geyer CR, DeCoteau JF: 5-Aza-2/-deoxycytidine (decitabine) can relieve p21WAF1 repression in human acute myeloid leukemia by a mechanism involving release of histone deacetylase 1 (HDAC1) without requiring p21WAF1 promoter demethylation. Leuk Res 2006, 30:69-76.

51. Lavelle D, Vaitkus K, Hankewych M, Singh M, DeSimone J: Effect of 5-aza -2/-deoxycytidine (Dacogen) on covalent histone modifications of chromatin associated with the $\varepsilon^{-}, \gamma^{-}$, and $\beta$-globin promoters in Papio anubis. Exp Hematol 2006, 34:339-347.

doi:10.1186/1471-2407-13-113

Cite this article as: Lim et al:: Development of a novel cell-based assay system EPISSAY for screening epigenetic drugs and liposome formulated decitabine. BMC Cancer 2013 13:113.

\section{Submit your next manuscript to BioMed Central and take full advantage of:}

- Convenient online submission

- Thorough peer review

- No space constraints or color figure charges

- Immediate publication on acceptance

- Inclusion in PubMed, CAS, Scopus and Google Scholar

- Research which is freely available for redistribution

Submit your manuscript at www.biomedcentral.com/submit
Ciomed Central 